\title{
Advances in layer-by-layer self-assembled coatings upon biodegradable magnesium alloys
}

\author{
Li-Jun $\mathrm{He}^{\dagger}$, Yang Shao ${ }^{\dagger}$, Shuo-Qi Li ${ }^{*}$, Lan-Yue Cui, Xiao-Jing Ji, Yan-Bin Zhao and \\ Rong-Chang Zeng ${ }^{*}$
}

\begin{abstract}
Magnesium (Mg) and its alloys are considered as ideal biodegradable materials due to their excellent mechanical properties and biocompatibility. In order to improve the surface properties to allow better adaptation to the surrounding tissue of the body, surface modification has played a significant role in satisfying multiple clinical requirements such as corrosion resistance, biocompatibility, and antibacterial ability. Here, layer-by-layer (LbL) self-assembly, which can be applied for biodegradable $\mathrm{Mg}$ alloys due to its extensive choice of usable units, holds great promise among all the surface techniques. In this review, the mechanisms of the driving force (i.e., electrostatic interaction, hydrogen bonding, charge transfer interaction and covalent bonding), cuttingedge advances in preparation methods (e.g., dipping, spraying, and spinning) and the functional properties (corrosion resistance, antibacterial activity, and biocompatibility) that could be achieved by the LbL coatings are summarized. A reasonable trend of the potential development of $\mathrm{LbL}$ for bio$\mathrm{Mg}$ alloys is also proposed at the end of this article.
\end{abstract}

Keywords: layer-by-layer assembly, coating, magnesium alloys, corrosion resistance, biocompatibility, antibacterial ability

\section{INTRODUCTION}

Due to the low standard electrode potential $(-2.372 \mathrm{~V} v s$. standard hydrogen electrode), magnesium ( $\mathrm{Mg})$ is prone to degrade in vitro and in vivo. The degradation products may be biocompatible to the surrounding tissues and can be absorbed or released by them with controllable dissolution rate of the alloys $[1,2]$. Thus, as a class of biodegradable metals, $\mathrm{Mg}$ alloys have great potential to be used as implant materials. This is also because the elastic modulus of $\mathrm{Mg}$ is close to that of human bone, which can effectively alleviate the "stress shielding" effect [3], and the density of $\mathrm{Mg}$ alloys is similar to the natural bone density. Thus the Mg would possess good biomechanical compatibility $[4,5]$.

However, $\mathrm{Mg}$ alloys possess disadvantages such as excessive degradation rate and severe localized corrosion in physiological environment, which reduce the mechanical strength of the implant, resulting in premature failure $[4,6,7]$. Furthermore, the release of hydrogen gas and the alkalization of microenvironment near the implant/tissue interfaces have potential harms to the growth of human bones and tissues, which limits the clinical applications of $\mathrm{Mg}$ alloys [8-10]. Since the interactions between cells and tissue occur at the tissue-implant interface, the focus has been cast over the preparation of surface films with sufficient corrosion resistance and biocompatibility. Antibacterial activity may also be required since the $\mathrm{Mg}$ implant may suffer bacterial infection after surgery [11].

At present, a variety of surface modification strategies, such as plasma electrolytic oxidization (PEO) or microarc oxidation (MAO) [12-16], chemical conversion coatings [17-21], ion implantation [11,22-25], electrochemical deposition [26-30] and layered double hydroxides (LDHs) [3,31,32], have been employed to manipulate the degradation of Mg-based implants in vitro and in vivo. However, their practical applications would be impeded by their disadvantages such as the relatively high energy consumption of MAO technology and the porosity of the resultant coating. Some chemical conversion coatings have limited protection for $\mathrm{Mg}$ alloys or may contain toxic chemicals. Ion implantation may cause

Corrosion Laboratory for Light Metals, College of Materials Science and Engineering, Shandong University of Science and Technology, Qingdao 266590, China

${ }^{\dagger}$ These authors contributed equally to this work.

* Corresponding authors (emails: lishuoqi@sdust.edu.cn (Li SQ); rczeng@foxmail.com (Zeng RC)) 
galvanic corrosion and accelerate the degradation of the $\mathrm{Mg}$ alloys [33]. At the same time, the biodegradable coatings on bio-Mg alloys should still be endowed with biocompatibility. Therefore, it is desirable for researchers to find an approach that can functionalize $\mathrm{Mg}$ alloy from more than one aspect.

Layer-by-layer (LbL) self-assembly is a technique that utilizes the principles of sequential deposition which relies on the interaction between the functional groups of different assembling units, so that the LbL assembly could lead to the formation of multilayers with various components [34]. The obtained multilayer film would possess specific function, stable performance, high structural integrity and complete surface coverage [31,32]. The LbL technique has been used to change the surface properties of the implants $[31,33,35]$. Compared with other methods, the most prominent feature of LbL technology is that multifunctional coating with homogenous structure could be realized by a convenient process [36,37]. In the context of the rapid development of surface modification for biodegradable Mg alloys, the bioactive surface with specific function could also be fabricated by LbL selfassembly of diverse molecules, such as drugs, proteins and polyelectrolytes. Therefore, LbL has received enormous attention from the scientists in the domain of biomedical Mg alloys.

The applications of LbL assembly on Mg alloys can be tracked to as early as 2011. Cai et al. [38] deposited a multilayer film containing poly(ethyleneimine) (PEI), poly(styrenesulfonate) (PSS) and 8-hydroxyquinoline (8HQ) on AZ91D Mg alloy by spin-assisted LbL technology to improve the corrosion resistance of $\mathrm{Mg}$ alloy. Our group has contributed dozens of articles regarding LbL coatings on Mg alloys since 2015 [39-44]. The investigations have been concentrated on the preparation of corrosion-resistant, antibacterial and biocompatible coatings on Mg alloys via LbL assembly.

To date, the number of literature, regarding functional LbL self-assembled coatings on $\mathrm{Mg}$ alloys, shows a remarkable increase. Hence, a systematic review is necessary to summarize the basic LbL strategies for the preparation of multifunctional coatings on $\mathrm{Mg}$ alloys, as shown in Fig. 1. Indeed, the successful construction of LbL self-assembled multifunctional coatings involves a comprehensive consideration of multiple factors: the specific requirement of functionalization, the characte-

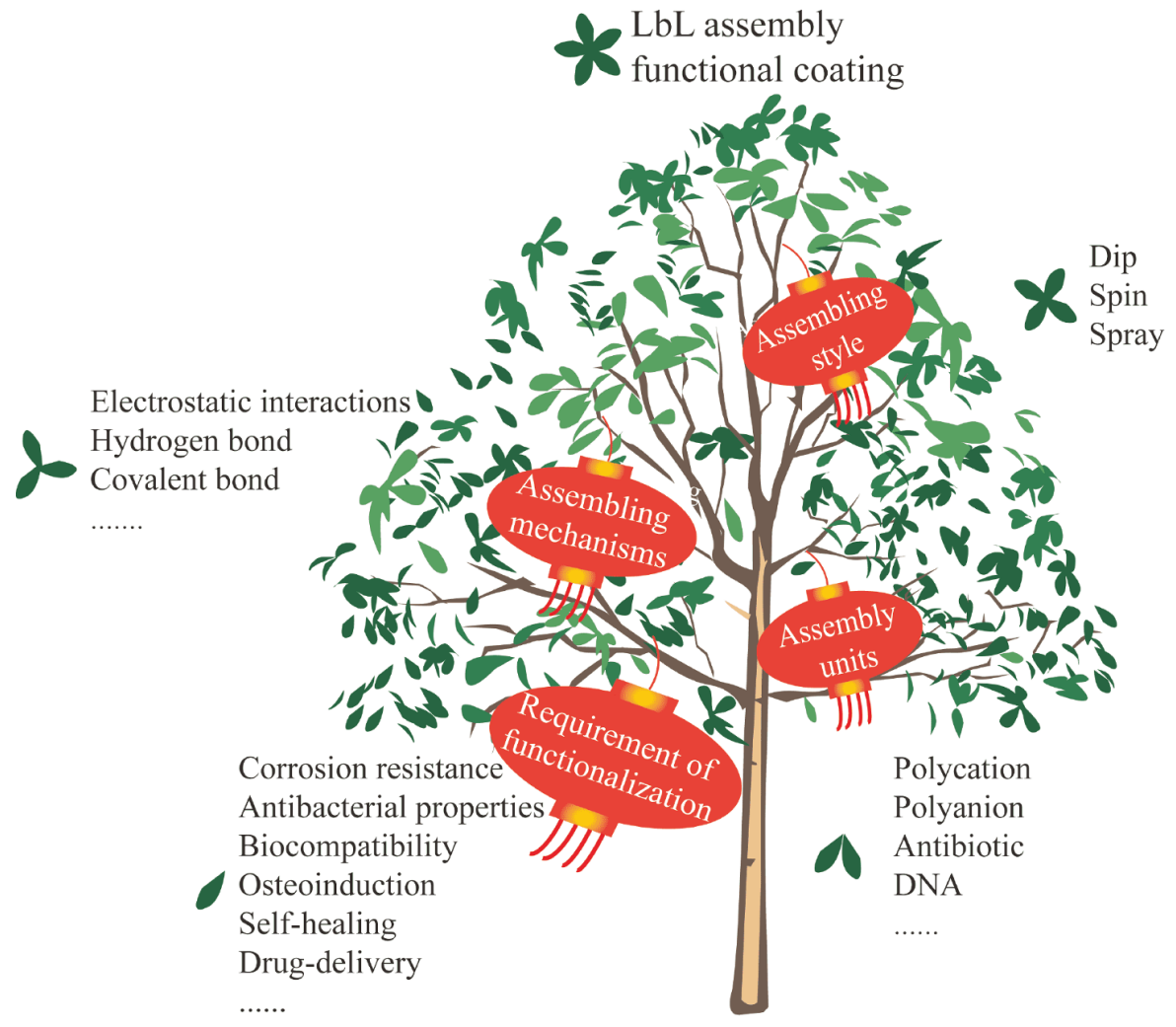

Figure 1 Schematic representation of the key factors in LbL assembly on Mg alloys. 
ristic of the assembly units, the assembling mechanisms and the assembling style.

\section{THE CLASSIFICATION OF THE DRIVING FORCES}

As presented in Fig. 2, there are four kinds of driving forces for LbL technology: electrostatic interaction, covalent bonding, hydrogen bonding and charge transfer interaction [39]. Nevertheless, the LbL assembly on the surface of $\mathrm{Mg}$ alloys is still mainly driven by electrostatic force.

\section{Electrostatic interaction}

Using electrostatic force as the driving force to build the multilayers is a relatively mature and common method for LbL technology [45]. It takes advantage of alternating adsorption and deposition between different electrolytes with opposite surface charges to form the assembled coatings on the substrate $[40,41,46]$. Specifically, the assembly process involves the immersion of the charged substrate into a solution containing the substances with opposite charges [42]. During the immersion, the substrate surface will absorb the charged substances and stratify them according to their electronegativity [43]. Fig. 3 shows the typical process for the LbL assembly based on electrostatic force on the surface of $\mathrm{Mg}$ alloy by dip coating method. The surface of Mg alloy was pretreated with $\mathrm{NaOH}$ solution to make the surface negatively charged, and then the sample would be soaked in a beaker containing polyelectrolytes with different charges.
The self-assembly will be driven by the electrostatic force between the polyelectrolytes. Thus, the layered structure will form with the alternative deposition. The thickness of the coating can be controlled by changing the number of assembled layers.

Recently, the preparation of multilayer via LbL technology driven by electrostatic interaction has become a popular method for surface modification of $\mathrm{Mg}$ alloys. The building blocks that could be charged in the LbL assembly are necessary [47,48], but there are still many types of assembly units that can be used. The assembly units used were polyelectrolytes and some charged small molecules (corrosion inhibitors, antibiotics) at first, and later various building blocks such as graphene and nanoparticles (NPs) that can be charged are also used. By spin-assisted LbL technology, Cai et al. [38] prepared a multilayer film composed of PEI, PSS and 8HQ (PEI/PSS/ 8HQ/PSS) on the AZ91D Mg alloy substrate. The $8 \mathrm{HQ}$ could act as the corrosion inhibitor. Ostrowski et al. [31] generated electrostatically assembled coatings containing anionic biodegradable polymers poly(lactide-go-glycolide) (PLGA) or polycaprolactone (PCL), cationic polymers PEI and polyallylamine hydrochloride (PAH) on AZ31 Mg alloy. This obtained coating shows long-term corrosion resistance and excellent biocompatibility. In the above studies, the assembly units are almost small molecules or polyelectrolytes, so the thickness of the multilayer is generally less than $1 \mu \mathrm{m}$. At the same time, the structure of multilayers is often loose and porous, which leads to the fact that the corrosive ions would penetrate

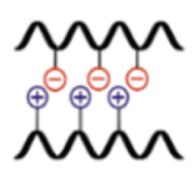

Electrostatic Interaction

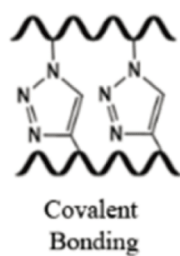

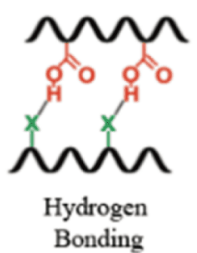

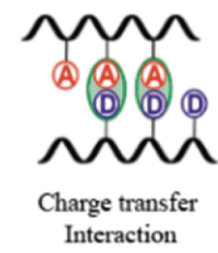

Figure 2 The possible interactions in the LbL assembly. Reprinted with permission from Ref. [34]. Copyright 2014, American Chemical Society.

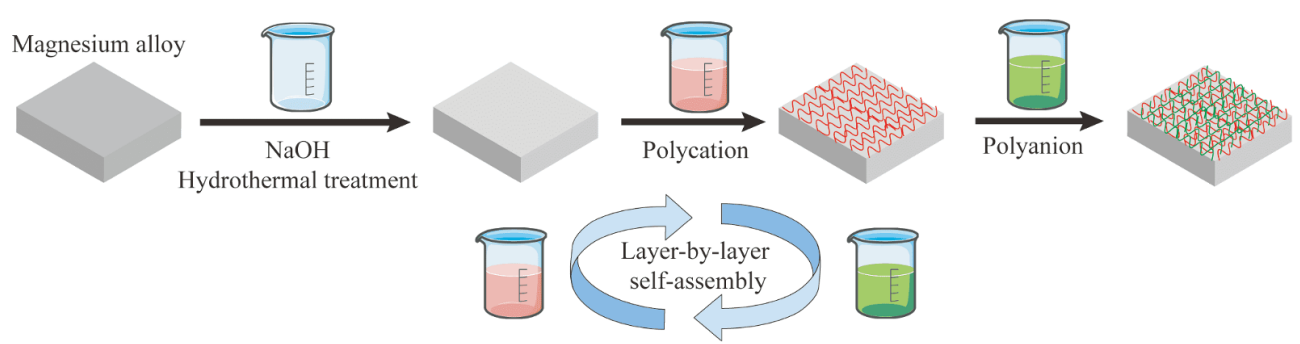

Figure 3 Schematic diagram of the LbL assembly of polyelectrolytes on Mg alloy surface by dip coating. 
into the alloy surface easily and the corrosion resistance of the entire film, especially the long-term corrosion resistance, is limited.

The use of NPs can achieve long-term corrosion resistance through the physical barrier effect, which is of great significance for improving the corrosion resistance of Mg alloys. This is proven in the fact that most of the following studies include hydrogen evolution experiments for hundreds of hours. The most typical assembly unit with corrosion resistance is the oxide particles. In Chen's work [49], the chitosan-gelatin containing $\mathrm{TiO}_{2}$ NPs could be alternatively deposited on MAO coating using LbL technique to improve the corrosion resistance of the Mg substrate. Ji et al. [50] prepared ciprofloxacin/ polyallylamine hydrochloride/ $\mathrm{SiO}_{2} /$ polyallylamine hydrochloride (abbreviated as $\mathrm{CIP} / \mathrm{PAH} / \mathrm{SiO}_{2} / \mathrm{PAH}$ ) multilayers on the surface of AZ31 Mg alloy by spin-spray LbL assembly. The presence of $\mathrm{SiO}_{2} \mathrm{NPs}$ not only improved the corrosion resistance of the substrate, but also endowed the coating with self-healing properties in which the particles can locate and effectively diffuse to the area of nanoscale cracks to repair the damaged regions [51]. The degradable graphene oxide (GO) is another optional assembly unit to improve corrosion resistance due to its high aspect ratio. Gao et al. [52] constructed a chitosanfunctionalized GO/heparin (GOCS/Hep) bioactive multilayer coating on the surface of AZ31B Mg alloy by LbL self-assembly technology. This coating not only provided excellent in vitro corrosion resistance for $\mathrm{Mg}$ alloy, but also remarkably reduced the hemolysis rate and platelet activation, reflecting exceptional biocompatibility. In Chen's work [53], GO was also employed in the LbLassembled PEI/phytic acid (PA)/PEI/GO coating, which could improve the resistance to degradation and stress corrosion cracking of the biomedical $\mathrm{Mg}$ - $\mathrm{Zn}$ alloy. Silver NPs (AgNPs) could be incorporated in the LbL multilayers. For example, Zhang et al. [54] used a polycationic copolymer with dopamine (DOP), 2-(methylacryloyloxyl) ethyl trimethylammonium chloride $\left(\mathrm{DMAEMA}^{+}\right)$and dextran sulfate (DS) capped to construct the [P(DOP)-co$\left.\mathrm{P}\left(\mathrm{DMAEMA}^{+}\right) / \mathrm{DS}-\mathrm{AG}\right]_{n}$ coating by means of spin-assisted LbL assembly. The corrosion resistance of the modified $\mathrm{Mg}$ alloy was effectively increased and the multilayer films on the $\mathrm{Mg}$ alloy surface showed significant antibacterial activity against $E$. coli and $S$. aureus [55].

Table 1 summarizes some representative examples of LbL multilayer films constructed on $\mathrm{Mg}$ alloys through electrostatic attraction between polyelectrolytes.

\section{Covalent bonding}

Covalent bond is stronger than any other intermolecular force [56]. It can be speculated that LbL-assembled coatings using covalent bonds as driving force may improve the stability and strength of the multilayer's structure [55]. The interaction between polyelectrolytes will inevitably involve the participation of covalent bonds. However, since the formation of covalent bonds takes time, they often cannot be the main driving force for assembly. He et al. [57] prepared a polydopamine/hyaluronic acid coating on $\mathrm{Mg}$ alloy by LbL assembly. The covalent bond between $-\mathrm{COOH}$ in hyaluronic acid and $-\mathrm{NH}_{2} /-\mathrm{OH}$ in polydopamine allowed them to be combined. The obtained coating improved the corrosion resistance of $\mathrm{Mg}$ alloys and could achieve a balance between biocompatibility and antithrombotic properties by adjusting the content of hyaluronic acid.

\section{Hydrogen bonding}

As an assembly driving force, hydrogen bonding compensates for the requirement of electrostatically driven LbL assembly technology for the electronegativity of polyelectrolytes. In 1997, Wang et al. [58] firstly proposed the hydrogen bonding-driven LbL self-assembly technology, which is a self-assembled thin film preparation method driven by hydrogen bonds. The preparation of

Table 1 LbL self-assembled coatings of Mg alloys surface with electrostatic force

\begin{tabular}{|c|c|c|c|c|}
\hline Materials & Multilayer film & Polycation & Polyanion & Ref. \\
\hline AZ91D Mg alloy & $(\mathrm{PEI} / \mathrm{PSS} / 8 \mathrm{HQ} / \mathrm{PSS})_{n}$ & PEI & PSS & [38] \\
\hline AZ31 Mg alloy & $(\mathrm{PEI} / \mathrm{PLGA} \text { or } \mathrm{PCL} / \mathrm{PAH})_{n}$ & PEI, PAH & PLGA or PCL & [31] \\
\hline $\mathrm{Mg}-3 \mathrm{Zn}-0.5 \mathrm{Sr}$ alloy & CS-HP- $n$ & CS-Gel $\left(\mathrm{TiO}_{2}\right)$ & HPs & [49] \\
\hline AZ31 Mg alloy & $\left(\mathrm{CIP} / \mathrm{PAH} / \mathrm{SiO}_{2} / \mathrm{PAH}\right)_{n}$ & $\mathrm{PAH}$ & CIP & {$[50]$} \\
\hline AZ31B Mg alloy & $(\mathrm{GOCS} / \mathrm{Hep})_{n}$ & GOCS & Hep & {$[52]$} \\
\hline $\mathrm{Mg}-1 \mathrm{Zn}$ alloy & $(b \mathrm{PEI} / \mathrm{GO} / b \mathrm{PEI} / \mathrm{PA})_{10}$ & $b$ PEI & GO,PA & [53] \\
\hline AZ31D Mg alloy & {$\left[\mathrm{P}(\mathrm{DOP})-c o-\mathrm{P}\left(\mathrm{DMAEMA}^{+}\right) / \mathrm{DS}-\mathrm{Ag}\right]_{n}$} & $\mathrm{P}(\mathrm{DOP})-c o-\mathrm{P}\left(\mathrm{DMAEMA}^{+}\right)$ & DS-Ag & {$[54]$} \\
\hline
\end{tabular}


functional films by this assembly technique has also been studied in many fields $[51,59]$. Nevertheless, there are few reports on preparing hydrogen bonding-driven LbLassembled coating on $\mathrm{Mg}$ alloys. In fact, like covalent bonds, hydrogen bonds often do exist in LbL assembly driven by electrostatic forces, but they often do not act as the key role.

Zhao et al. [60] successfully prepared polyvinylpyrrolidone (PVP)/polyacrylic acid (PAA) multilayer composite coating by spin-casting LbL technology on AZ31 Mg alloy. From the Fourier transformed infrared spectroscopy (FT-IR) data, it was found that the stretching frequency of $\mathrm{C}=\mathrm{O}$ was red-shifted, indicating that hydrogen bond was formed between PVP and PAA. Chu et al. [61] prepared a homogeneous reduction $\mathrm{GO} /$ polyvinyl alcohol (RGO/PVA) coating on $\mathrm{Mg}-6.0 \mathrm{Zn}$ $0.5 \mathrm{Ca}$ alloy, and revealed that a hydrogen bond network was formed between the PVA chain and the RGO sheet, which made the coating structure dense and orderly. Therefore, the coating on $\mathrm{Mg}$ alloy shows enhanced corrosion resistance and excellent wear resistance. In the above work, the hydrogen bonding is actually not the primary force for film formation, but as a driving force for adjusting the compactness of the entire coating or tuning the orientation of the assembly units.

Interestingly, the characteristic of hydrogen bonding is somehow similar to the "degradability" of Mg alloys. In most cases, biomedical coatings on $\mathrm{Mg}$ alloys begin to dissolve once being implanted in the patient's body [62], resulting in an uncontrollable degradation process. It is envisioned that in future studies, a novel biomedical coating could be developed using the influence of $\mathrm{pH}$ value and other factors on hydrogen bonding. When the patient recovers, a slight increase in $\mathrm{pH}$ value will lead to the failure of "hydrogen bond coating" and accelerate the degradation of $\mathrm{Mg}$ implants, so as to achieve the effect of both the recovery of the patient and the degradation of the implant $[51,58,59]$.

\section{Charge transfer interaction}

Charge transfer is a weak interaction of partial electron transfer within or between molecules, which can act as a driving force for the LbL assembly of two non-ionic polymers to assemble thin films [63].

Nevertheless, there are no reports regarding LbL assembly coating on Mg alloy via charge transfer interaction. This may be due to the relatively weak strength of the force, which is easily destroyed in polar solvents and high-concentration salt solutions. However, it is believed that the charge transfer interaction can still obtain bright application prospects for LbL assembly coatings on $\mathrm{Mg}$ alloys. Coatings prepared solely by charge transfer may be vulnerable to breakage, but the inherent properties of the two materials (electron donor-electron acceptor) could be used in combination with LbL assembly techniques to produce microcapsules [64] or films [65]. This might lead to a variety of physical and chemical properties on $\mathrm{Mg}$ alloys.

As can be seen from the previous description, different types of molecular forces would endow the $\mathrm{Mg}$ alloys with different advantages and disadvantages, which could be summarized in Table 2.

Table 2 Comparison of advantages and disadvantages of four intermolecular forces

\begin{tabular}{|c|c|c|c|}
\hline Molecular interaction & Advantage & Disadvantage & Ref. \\
\hline $\begin{array}{l}\text { Electrostatic } \\
\text { interaction }\end{array}$ & $\begin{array}{l}\text { Fabrication process performed in aqueous } \\
\text { solution, which is relatively simple; wide selection } \\
\text { of assembly materials, and not limited by size, } \\
\text { shape, type; coating thickness and properties } \\
\text { can be precisely controlled }\end{array}$ & $\begin{array}{c}\text { Only applicable to assembly of charged PELs in } \\
\text { aqueous solution; it is easy to be affected } \\
\text { by ion strength and other factors during } \\
\text { assembly process, and the detection procedure is } \\
\text { expensive, which requires high accuracy of the } \\
\text { instrument }\end{array}$ & {$[40-43,46-48]$} \\
\hline Covalent bonding & $\begin{array}{l}\text { The coating has good stability and resistance to } \\
\text { external pH, temperature and ionic strength; } \\
\text { different functional groups can be assembled } \\
\text { into the coating effectively; the assembly process } \\
\text { can occur not only in aqueous solutions but } \\
\text { also in organic solvents }\end{array}$ & $\begin{array}{l}\text { Different assembled molecules may react } \\
\text { with each other, bringing impurities to the } \\
\text { coating; low output, complicated and } \\
\text { expensive methodology }\end{array}$ & {$[66-69]$} \\
\hline Hydrogen bonding & $\begin{array}{l}\text { Functional molecules with no charge can be } \\
\text { assembled by hydrogen bond; it could prepare } \\
\text { layered and erasable polymer multilayers; ensure } \\
\text { high directionality and structural diversity }\end{array}$ & $\begin{array}{l}\text { LbL-assembled multilayer films prepared with } \\
\text { this driving force have lower binding force } \\
\text { and less stability than other intermolecular } \\
\text { interactions; easily affected by pH value and } \\
\text { temperature }\end{array}$ & {$[58,70,71]$} \\
\hline $\begin{array}{l}\text { Charge transfer } \\
\text { interaction }\end{array}$ & $\begin{array}{l}\text { Multilayer films can be achieved by assembling } \\
\text { nonionic molecules; can be assembled in organic } \\
\text { solvents; multilayer film is easily detected by } \\
\text { spectroscopic technique }\end{array}$ & $\begin{array}{l}\text { Limited to electron donating and } \\
\text { accepting groups of non-ionic molecules }\end{array}$ & {$[65,72,73]$} \\
\hline
\end{tabular}




\section{THE ASSEMBLING STYLES}

LbL self-assembly technology is an effective method for preparing multilayer films with controllable structures and compositions [74]. Its assembly process, as shown in Fig. 4, can be divided into three categories: dip, spin [75] and spray coating $[76,77]$.

Dip coating is to prepare multilayer films by alternately immersing the substrate in a solution containing an interactive compound. In addition, a rinsing step is added between two consecutive adsorption steps to remove cross-contamination caused by weak adsorbents during the assembly process [79]. However, in practical applications, the adsorption, interaction, and rinsing steps between electrolytes will make the assembly process more cumbersome, which is not conducive to the rapid and efficient preparation of functional multilayers. Therefore, researchers tried to simplify the assembly process by skipping the rinse step. Shim et al. [80] proposed a new assembly method based on the phenomenon of dewetting

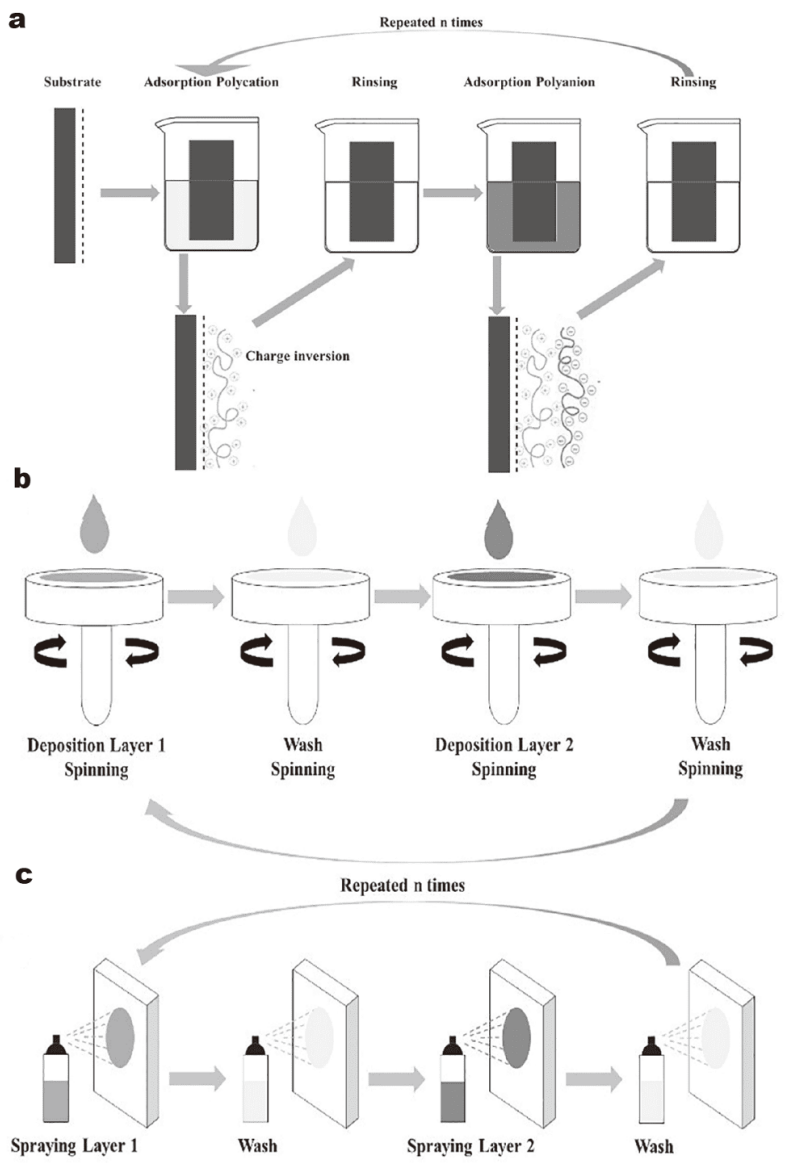

Figure 4 Illustration of fabrication processing of LbL self-assembled coatings using dip (a), spin (b) and spray-assisted methods (c). Reprinted with permission from Ref. [78]. Copyright 2020, Elsevier Ltd.
[81]. Specifically, dimethylformamide, an organic solvent, was doped into the solution of the adsorption compound. With the evaporation of solvent, excess material was eliminated and the rinsing step was omitted, which greatly accelerated the LbL assembly process. Anyway, since the dipping method needs to be carried out in the solution system, the process of molecular diffusion, adsorption, and deposition on the substrate surface requires a certain amount of time, making the entire self-assembly process time-consuming $[82,83]$.

For this reason, spin coating and spray-assisted coating have been proposed to speed up the preparation process and overcome the disadvantages of dip method.

Spin coating refers to rotating the substrate at a constant speed and then dropping a solution containing the assembled units onto the substrate [84]. Since the substrate is always in a rotating state, the solvent on its surface evaporates quickly, ensuring that the film remains dry. The multilayer film prepared by the spin coating method has a lower roughness and better organization than that prepared by the dip coating method, and the interpenetration between adjacent layers is lower [85].

The spin coating process involves complex interactions between electrostatic force, centrifugal force, air shear force and viscous force. Both spinning speed and solution concentration will change the thickness of the multilayers and affect the coating's performance. It is worth mentioning that under the shear force, the building blocks could be rearranged to form the dense and compact structure [60], which would be beneficial for improving the corrosion resistance of based alloys.

It is the spin method that speeds up the diffusion process between the assembled substances. The efficiency of LbL assembly is greatly improved by accelerating the diffusion process between assembled materials and shortening the treatment time to reach adsorption equilibrium. Nevertheless, the defects of spin coating should not be underestimated. The main problem of spin coating is that the most common low-volatility assembly solvent, water, cannot be removed from the assembly process. In response to this problem, a heating device can be added to the spin coating method to promote the volatilization of water.

Schlenoff et al. [86] firstly introduced the approach of spraying to prepare LbL multilayer film in 2000. Spraying is a fast and efficient LbL assembly method, which quickly and thoroughly mixes the newly entered polyelectrolyte solutions with the underlying membrane by spray. Generally speaking, spraying could be divided into two categories: alternate spraying and simultaneous spraying 
[87] (Fig. 5). Spraying results in rapid interactions between complementary materials on the surface, leading to continuous growth and gradual accumulation of the coating [88]. The thickness is controlled by the spraying time, while the solvent and excess substances are removed by drainage [89]. In a word, the spraying method is simple and widely applicable, while the practical application to the surface of $\mathrm{Mg}$ alloy should also depend on the self-assembly material to choose appropriate spraying time, solution concentration, nozzle type, spraying rate, spraying distance, and so on.

Therefore, the flexible but powerful LbL assembly process needs to be further optimized in the respect such as assembly time, temperature, solution concentration and other parameters to quickly adapt to the needs of preparing different coatings on $\mathrm{Mg}$ alloys.

Based on the practical problems of surface modification on $\mathrm{Mg}$ alloys, the LbL assembly should be considered from the following aspects to prepare multifunctional LbL coatings on Mg alloy. (1) Function design for the possible coating; (2) selection of the appropriate assembly units; (3) plan for the binding force and assembly process parameters; (4) selection of the assembling style.

\section{THE FUNCTIONALIZATION OF SELF- ASSEMBLED COATINGS}

Due to the diversity of assembled blocks in LbL, we can endow the $\mathrm{Mg}$ alloy substrate with different functions by selecting appropriate units. These multilayer coatings often enable the substrate to exhibit multiple functions, which could be classified into the following types (Fig. 6).

\section{Corrosion-resistant coatings}

The LbL technology has proved to be an effective way to increase the corrosion resistance of Mg alloys. In Fig. 7, the LbL multilayer film acts as a physical barrier, effectively separating most of the corrosive anions and oxidants from the surface or prolonging the penetration path

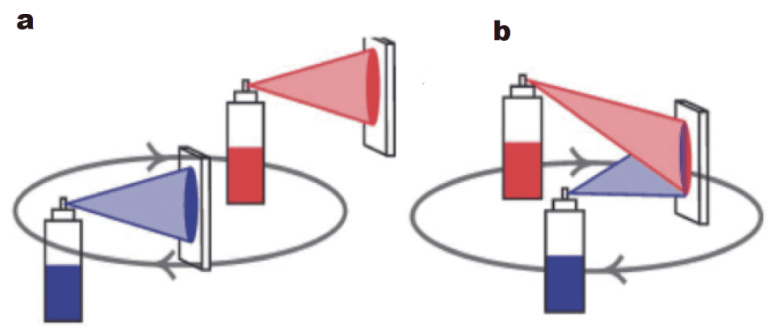

Figure 5 Two types of spraying: (a) alternate spraying and (b) simultaneous spraying. Reprinted with permission from Ref. [87]. Copygight 2014, The Royal Society of Chemistry.

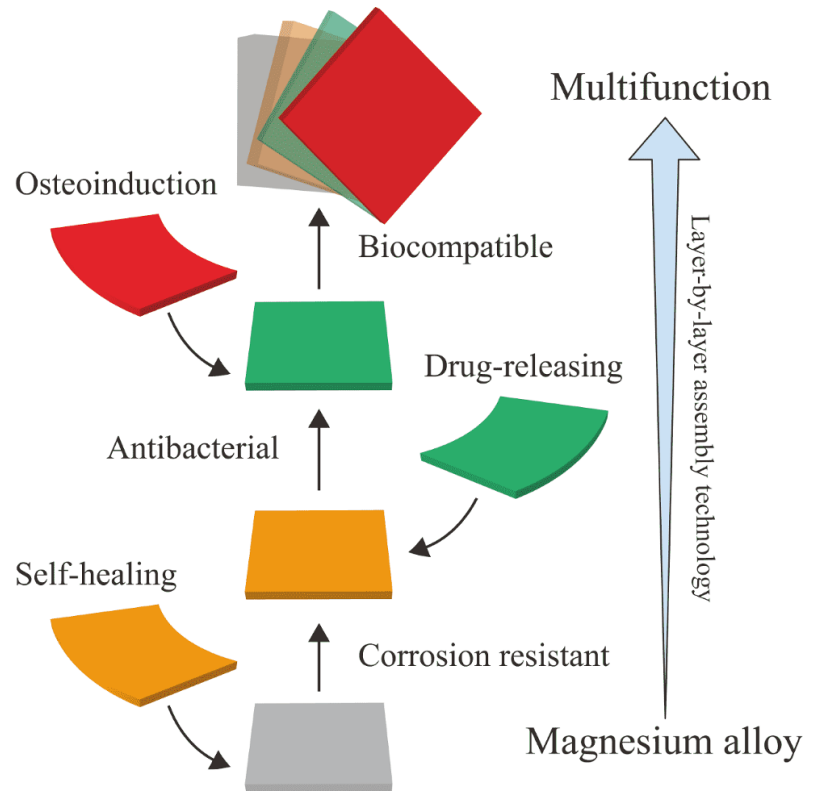

Figure 6 Potential medical requirements that could be achieved LbL self-assembly.

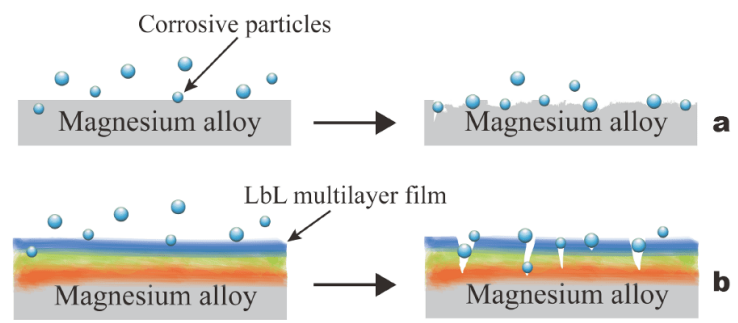

Figure 7 Schematic illustration of the corrosion mechanism of the $\mathrm{Mg}$ alloy (a) and coated Mg alloy (b).

of the corrosive species. However, the LbL assembly process itself often has a corrosive effect on the Mg alloy or $\mathrm{Mg}(\mathrm{OH})_{2}$ surface $[36,44]$. Therefore, the low thickness or porous structure of the LbL multilayers would not effectively reduce the corrosion rate of the substrate. Thus, in order to separate the matrix and the corrosion medium as much as possible, various potential factors need to be considered to modulate the multilayer film structure. These factors include the number of assembled layers, the cross-linking between the building units, the separation effect of NPs, the use of the molecules with functional groups that can induce precipitation, and so on.

The number of assembled layers is a key factor in practical production. Cui et al. [90] fabricated (PVP/ DNA $)_{n},(n=5,10,20,40)$ multilayer films on AZ31 Mg alloy via dip-coating LbL technique. The results indicated 
that, among the four multilayers with different bilayer numbers, the (PVP/DNA) 20 possessed the highest corrosion resistance. In addition to the separation effect of the multilayer film, the corrosion resistance also comes from the induction effect of the phosphate functional group in the DNA on the formation of Ca-P products [91], which would act as a physical barrier to protect the AZ31 substrate from corrosion.

Gao et al. [92] fabricated the (chitosan/heparinized $\mathrm{GO})_{5}\left((\mathrm{Chi} / \mathrm{HGO})_{5}\right)$ multilayer coating on AZ31B Mg alloy by dip-coating LbL method. The electrochemical analysis and immersion test demonstrated that the prepared multilayer coating could effectively improve the corrosion resistance of the substrate. Furthermore, heparin inhibited the platelet aggregation, thereby improving the blood compatibility of Mg alloy [93]. Chitosan and heparin also benefit the adhesion and proliferation of endothelial cells $[94,95]$. The approach of this study may open up a new window of modifying the surface of $\mathrm{Mg}$ based implants, such as intravascular stents.

Chen et al. [96] prepared a $\left(\mathrm{CeO}_{2} / \mathrm{PEI} /\right.$ carboxymethyl cellulose and GO $)_{10}\left(\mathrm{CeO}_{2} /(\mathrm{PEI} / \mathrm{CMC} @ \mathrm{GO})_{10}\right)$ multilayer film on AZ31 $\mathrm{Mg}$ alloy through a dip-coating $\mathrm{LbL}$ method. The corrosion current density $\left(i_{\text {corr }}\right)$ of the $\mathrm{CeO}_{2} /$ (PEI/CMC@GO) ${ }_{10}$ coating $\left(5.071 \mu \mathrm{A} \mathrm{cm}{ }^{-2}\right)$ was obviously lower than that of the native AZ31 $\left(53.96 \mu \mathrm{A} \mathrm{cm}^{-2}\right)$ and the free corrosion potential $\left(E_{\text {corr }}\right)$ of the multilayer film increased by $0.133 \mathrm{~V}$. Zhang et al. [97] constructed a multilayer coating induced by green tea phenol-metal $\left(\mathrm{Mg}^{2+}\right.$ incorporated epigallocatechin gallate) on AZ31 Mg alloy using dip-coating LbL technology. The coated samples showed enhanced corrosion protection and desired biocompatibility, and could be expected to be used as biodegradable cardiovascular implants. Zhao et al. [98] fabricated a $\left(\mathrm{SiO}_{2} / \mathrm{CeO}_{2}\right)_{10}$ composite coating on the AZ31 substrate via dip-coating LbL and spin-assisted LbL technique, respectively. In comparison with dip-coating LbL, the multilayer film obtained by spin-assisted LbL was denser, smoother and could provide better corrosion resistance. Meanwhile, the film with $\mathrm{CeO}_{2} \mathrm{NPs}$ possessed self-healing effects. This work provides a new strategy for the deposition of nanocapsules with tunable self-healing and drug delivery properties on $\mathrm{Mg}$ alloys.

Table 3 summarizes some representative examples of the construction of multilayer films using LbL selfassembly technology to impart corrosion resistance to $\mathrm{Mg}$ alloy substrates. For each group, the values of $i_{\text {corr }}$ and $E_{\text {corr }}$ varied with substrates, electrolytes and immersion periods were listed.

\section{Antibacterial coatings}

After the insertion of orthopedic or dental Mg implants, the infection due to the formation of biofilm would be a severe complication which could lead to the local tissue lesions and failure of implant materials [99-101]. Actually, the antibiotics can be used to reduce the infections along with the surgery. However, the misuse of the antibiotics would lead to the emergence of antibioticresistant bacterial strains [102], which also increases the suffering of the patients and brings great pressure on patient's psychology, economy and family $[103,104]$. Thus, it has become an important issue to develop composite coating on the surface of $\mathrm{Mg}$ alloy which can prevent bacterial adhesion and colonization. In this domain, the LbL-assembled multilayers have been applied for the development of antibacterial coatings. As illustrated in Fig. 8, the antibacterial coatings could act in two ways by release-killing and release contact-killing [105]. Typically, release-killing capacity is introduced to an LbL surface by incorporating bacteria-killing substances such as antibiotics, antibacterial peptides, heavy metals and NPs with bactericide action [106]. The antibacterial units in the LbL coating would always display the initial burst release and subsequent sustained release [107].

AgNPs are antibacterial units that are easy to be as-

Table 3 Electrochemical parameters of multilayer coatings on AZ31 Mg alloy

\begin{tabular}{|c|c|c|c|c|c|c|c|}
\hline \multirow{2}{*}{ Coating } & \multirow{2}{*}{ Solution } & \multirow{2}{*}{ Thickness $(\mu \mathrm{m})$} & \multicolumn{2}{|c|}{$E_{\text {corr }}(\mathrm{V} / \mathrm{SCE})$} & \multicolumn{2}{|c|}{$i_{\text {corr }}\left(\mu \mathrm{A} \mathrm{cm}^{-2}\right)$} & \multirow{2}{*}{ Ref. } \\
\hline & & & Substrate & Coating & Substrate & Coating & \\
\hline$(\mathrm{PVP} / \mathrm{DNA})_{20}$ & SBF & - & -1.74 & -1.53 & 84.30 & 4.71 & [90] \\
\hline$(\mathrm{Chi} / \mathrm{HGO})_{5}$ & SBF & 0.755 & -1.801 & -1.376 & 88.63 & 0.7483 & [92] \\
\hline $\begin{array}{c}\mathrm{CeO}_{2} /(\mathrm{PEI} / \\
\mathrm{CMC} @ \mathrm{GO})_{10}\end{array}$ & $3.5 \% \mathrm{NaCl}$ & - & -1.539 & -1.406 & 53.96 & 5.071 & [96] \\
\hline EGCG ${ }^{\mathrm{a}} / \mathrm{Mg}$ & $\mathrm{SBF}^{\mathrm{b}}$ & $24.5+0.6$ & -1.39 & -1.45 & 16.20 & 0.104 & [97] \\
\hline$\left(\mathrm{SiO}_{2} / \mathrm{CeO}_{2}\right)_{10}$ & HBSS $^{c}$ & 0.630 & $-1.463 \pm 0.006$ & $-1.366 \pm 0.016$ & $8.073 \pm 0.221$ & $0.758 \pm 0.105$ & [98] \\
\hline
\end{tabular}

a) EGCG: epigallocatechin gallate; b) SBF: simulated body fluid; c) HBSS: Hank's Balanced Salt Solution. 

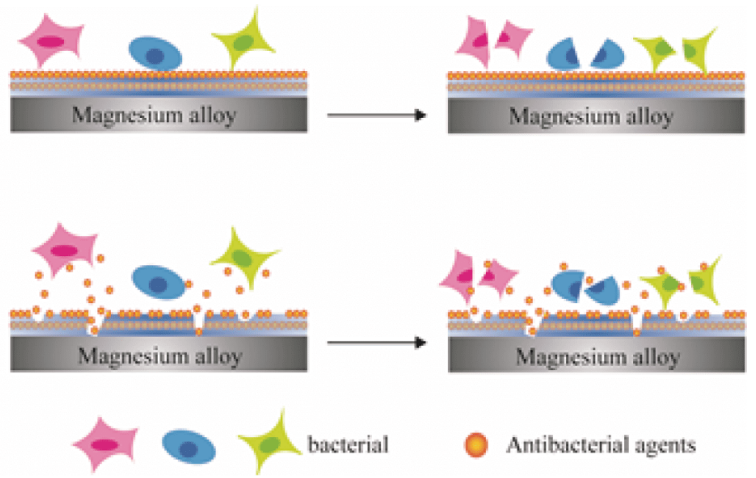

Figure 8 Schematic diagram of the multilayer coating-modified $\mathrm{Mg}$ alloy for inhibiting the colonization of bacteria via contact-killing and release-killing.

sembled. Zhang et al. [54] fabricated the antibacterial coating containing AgNPs via spin-assisted LbL on AZ31D alloy pretreated by MAO. The silver ions released by the multilayers exhibited good inhibitory effect on the growth of bacteria [108]. Wang et al. [109] successfully prepared antibacterial coating containing AgNPs and chitosan on AZ31 Mg alloy via the dip-coating LbL process. The obtained coating significantly enhanced the corrosion resistance of the substrate and also showed excellent antibacterial activity due to the synergetic effect of AgNPs and chitosan [110,111]. This coating strategy may be also extended to the design of many other orthopedic devices. However, AgNPs would always cause $\mathrm{Mg}-\mathrm{Ag}$ galvanic corrosion, which would increase the degradation rate of the $\mathrm{Mg}$ substrate and some other extra functional materials may be needed to compensate this result [112]. In Zhao's work [113], the multilayers containing AgNPs on AZ31 substrate were hybridized with polysiloxane, which would provide anti-corrosion ability and self-healing effect for the substrate.

The antibiotic agents could also be loaded on $\mathrm{Mg}$ surface via LbL. Zeng et al. [35] prepared a multilayer film containing gentamicin sulfate (GS) on the surface of $\mathrm{Mg}(\mathrm{OH})_{2}$. The obtained sample exhibited antibacterial function, but at the same time, the multilayer film will accelerate the corrosion rate of the $\mathrm{Mg}$ substrate. Ji et al. [114] constructed the CIP-loaded multilayers on AZ31 $\mathrm{Mg}$ alloy through dip-LbL, and then prepared a hydroxyapatite coating by hydrothermal treatment. The composite coating showed $98.7 \%$ and $95.2 \%$ antibacterial activities against $E$. coli and $S$. aureus due to the release of CIP [115]. Zhao et al. [116] fabricated a multilayer film containing GS on AZ31 Mg alloy by the spin-assisted LbL method and heat treatment. The Mg alloy was endowed with good antibacterial properties owing to the release of
GS [117].

Alternatively, the $\mathrm{Mg}$ surface can also obtain the contact bacteria-killing ability by LbL with tethered bactericidal functionalities which are able to kill bacteria upon contact. Cui et al. [44] constructed an antimicrobial coating with chitosan as the polycation and poly- $L$-glutamic acid as the polyanion on AZ31Mg alloy. The antibacterial results suggested that the coating has a favorable inhibitory effect on the growth of $S$. aureus. Normally, the surface of bacterial cells is negatively charged, while chitosan has polycation nature, and it can interfere with bacterial metabolism through electrostatic attraction, resulting in bacterial contact death [118]. Although chitosan shows a certain antibacterial ability, its inherent antibacterial ability is relatively mild, and only under specific $\mathrm{pH}$ conditions, its antibacterial ability can be fully reflected, which greatly limited the exertion of antibacterial ability of chitosan. At present, chemical modification of amino or hydroxyl groups on the surface of chitosan or the addition of external antibacterial factors are the main methods to improve the antibacterial properties of chitosan materials $[119,120]$.

\section{Biocompatible coatings}

$\mathrm{Mg}$ alloy possesses no critical toxic limits, and no side effects have been reported for the $\mathrm{Mg}^{2+}$ ions released during the degradation process [121]. However, since the immobilized substances of a coating on the Mg surface may have a negative effect on the biocompatibility of the $\mathrm{Mg}$ substrate, in vitro and in vivo analysis should be performed to verify the feasibility of the implant [17]. Therefore, in the LbL for $\mathrm{Mg}$, it is necessary to avoid the use of biologically toxic substances. Quan et al. [122] constructed the poly- $\beta$-hydroxybutyrate (PHB) coating containing vascular endothelial growth factor (VEGF) and heparin on the surface of WE Mg (Mg-4.1Y-2.8Nd$0.2 \mathrm{Zn}-0.4 \mathrm{Zr}$ ) alloy using the LbL approach. The bioactive coating can effectively inhibit platelet adhesion and activation, thereby reducing the thrombosis. Meanwhile, the coated $\mathrm{Mg}$ alloy has a lower adsorption capacity of fibrinogens, which reduces the hemolysis rate and prolongs the clotting time, demonstrating that the sample has better blood compatibility. Furthermore, the sample with bioactive film shows cytocompatibility, which significantly improves cell adhesion and promotes the growth of the cells.

More importantly, the multilayers could be hybridized with other biocompatible coatings to achieve biosafety of the sample. Hydroxyapatite (HA) is a coating system that is easy to be hybridized with LbL multilayer films. Ji et al. 


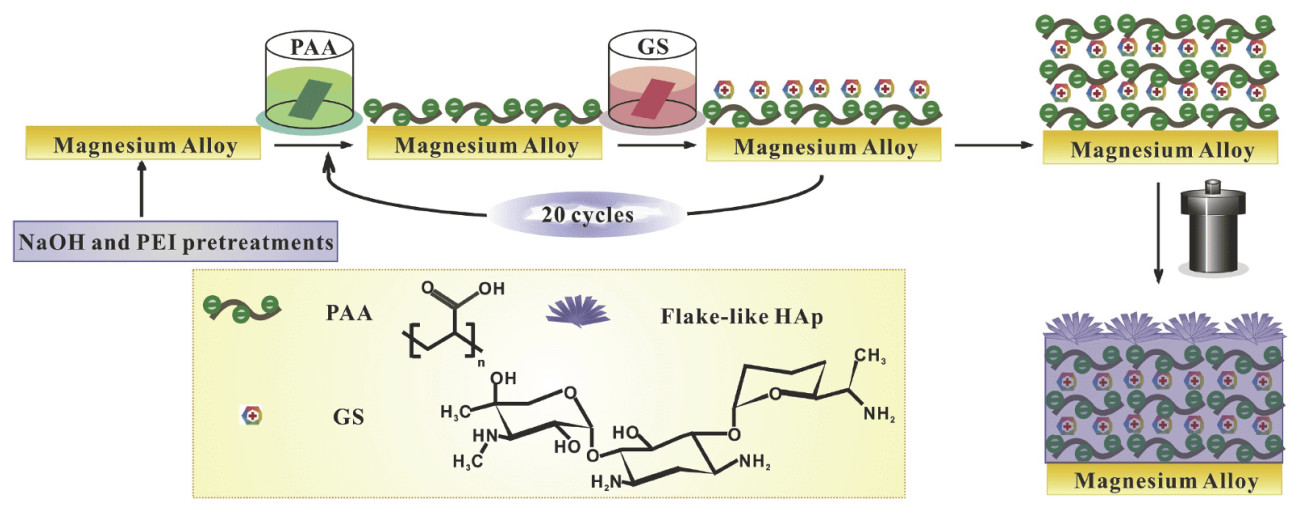

Figure 9 Schematic representation of the preparation of (PAA/GS) ${ }_{20} / \mathrm{PAA}-\mathrm{HAp}$ coating. Reprinted with permission from Ref. [123]. Copyright 2019, Elsevier Ltd.

[123] fabricated a GS-loaded multilayer film on AZ31 Mg alloy by dip LbL assembly, and then the HA coating was induced by a hydrothermal method. The composite coating exhibited corrosion resistance and antibacterial effects. The coated $\mathrm{Mg}$ alloy showed acceptable biocompatibility to MC3T3-E1 osteoblasts. Similarly, Cui et al. [124] generated a polyelectrolyte-induced Ca-P coating based on PVP and PAA through the LbL assembly method. The LbL-assembled template can induce a biomineralized Ca-P coating. And the final coating displays a good corrosion protection for AZ31 Mg alloy. As shown in Fig. 9, PAA with abundant carboxylate groups can interact with $\mathrm{Ca}^{2+}$ ions in the hydrothermal solution via molecular recognition, which is conducive to the formation of Ca-P coating.

\section{Coatings with other functions}

Actually, according to the specific features of the assembly units involved in the LbL process, the LbL-assembled multilayers can also be endowed with other functionalities such as self-repairing ability, and osteoinductive capability. Fan et al. [125] used the PEI/PAA multilayer to provide the self-healing ability to the coating systems on AZ31 Mg alloy. The cross-linking based on electrostatic attraction and swelling ability of PEI and PAA plays an important role in the self-healing process. Liu et al. [126] successfully generated a $\mathrm{PA} / \mathrm{Ca}^{2+}$ multilayer coating on the Mg-Sr alloy by the LbL method. The $\mathrm{Ca}^{2+}$ ions in the coating induce the formation of apatite and favor the proliferation of osteoblasts. Moreover, the alkaline phosphatase activity of the coated sample increases obviously, which is beneficial to bone healing.

\section{SUMMARY AND PERSPECTIVES}

LbL assembly is an effective technique to improve the performance (degradation rate, antibacterial ability, and biocompatibility) of Mg alloys. Although there are many types of driving forces that can be used for LbL assembly, electrostatic forces are still the most widely used. The assembly of small molecules and polyelectrolytes often fails to provide corrosion resistance, and multilayer films need to be embedded with NPs or hybridized with other coatings to effectively reduce the corrosion rate of $\mathrm{Mg}$ alloy substrates. The obtained LbL-assembled multilayers would also display their own characteristics according to the specific functions of the building blocks, such as antibacterial property and biocompatibility. In practical applications, biomedical $\mathrm{Mg}$ alloys usually require a combination of several properties together, while the LbL assembly technology is expected to achieve this goal.

To be sure, there are still many disadvantages to overcome before the clinical application of LbL. The preparation process takes much more time and the multilayers show weak adhesion to $\mathrm{Mg}$ alloys. It is very likely that it is difficult to achieve all the required functions by merely adopting LbL assembly, but with its specific characteristics in functionalizing, this technology can endow other coatings with a specific bioactivity. Future work should also focus on the comprehensive evaluation of the LbL sample, and the automation of the fabrication process is necessary to save time.

\section{Received 6 August 2020; accepted 5 March 2021; published online 27 May 2021}

1 Liu Y, Zheng YF, Chen XH, et al. Fundamental theory of biodegradable metals-definition, criteria, and design. Adv Funct Mater, 2019, 29: 1805402

2 Witte F. The history of biodegradable magnesium implants: A review. Acta Biomater, 2010, 6: 1680-1692

3 Yan W, Lian YJ, Zhang ZY, et al. In vitro degradation of pure magnesium-the synergetic influences of glucose and albumin. 
Bioactive Mater, 2020, 5: 318-333

4 Kannan MB, Raman RKS. In vitro degradation and mechanical integrity of calcium-containing magnesium alloys in modifiedsimulated body fluid. Biomaterials, 2008, 29: 2306-2314

5 Yang YX, Fang Z, Liu YH, et al. Biodegradation, hemocompatibility and covalent bonding mechanism of electrografting polyethylacrylate coating on $\mathrm{Mg}$ alloy for cardiovascular stent. J Mater Sci Tech, 2020, 46: 114-126

6 Kirkland NT, Lespagnol J, Birbilis N, et al. A survey of biocorrosion rates of magnesium alloys. Corrosion Sci, 2010, 52: 287-291

7 Ding ZY, Cui LY, Zeng RC, et al. Exfoliation corrosion of extruded Mg-Li-Ca alloy. J Mater Sci Tech, 2018, 34: 1550-1557

8 Kim SM, Jo JH, Lee SM, et al. Hydroxyapatite-coated magnesium implants with improved in vitro and in vivo biocorrosion, biocompatibility, and bone response. J Biomed Mater Res, 2014, 102: 429-441

9 Zhang N, Zhao D, Liu N, et al. Assessment of the degradation rates and effectiveness of different coated $\mathrm{Mg}-\mathrm{Zn}-\mathrm{Ca}$ alloy scaffolds for in vivo repair of critical-size bone defects. J Mater SciMater Med, 2018, 29: 138

10 Yin ZZ, Qi WC, Zeng RC, et al. Advances in coatings on biodegradable magnesium alloys. J Magnesium Alloys, 2020, 8: 4265

11 Zhao Y, Jamesh MI, Li WK, et al. Enhanced antimicrobial properties, cytocompatibility, and corrosion resistance of plasmamodified biodegradable magnesium alloys. Acta Biomater, 2014, 10: 544-556

12 Gao JH, Shi XY, Yang B, et al. Fabrication and characterization of bioactive composite coatings on $\mathrm{Mg}-\mathrm{Zn}$-Ca alloy by $\mathrm{MAO} /$ sol-gel. J Mater Sci-Mater Med, 2011, 22: 1681-1687

$13 \mathrm{Gu} \mathrm{XN}, \mathrm{Li} \mathrm{N}$, Zhou WR, et al. Corrosion resistance and surface biocompatibility of a microarc oxidation coating on a $\mathrm{Mg}-\mathrm{Ca}$ alloy. Acta Biomater, 2011, 7: 1880-1889

14 Wu C, Wen Z, Dai C, et al. Fabrication of calcium phosphate/ chitosan coatings on AZ91D magnesium alloy with a novel method. Surf Coat Tech, 2010, 204: 3336-3347

15 Yao $\mathrm{Z}$, Li L, Jiang $\mathrm{Z}$. Adjustment of the ratio of $\mathrm{Ca} / \mathrm{P}$ in the ceramic coating on $\mathrm{Mg}$ alloy by plasma electrolytic oxidation. Appl Surf Sci, 2009, 255: 6724-6728

16 Zhang XP, Zhao ZP, Wu FM, et al. Corrosion and wear resistance of AZ91D magnesium alloy with and without microarc oxidation coating in Hank's solution. J Mater Sci, 2007, 42: 8523-8528

17 Ali M, Elsherif M, Salih AE, et al. Surface modification and cytotoxicity of Mg-based bio-alloys: An overview of recent advances. J Alloys Compd, 2020, 825: 154140

18 Chen XB, Yang HY, Abbott TB, et al. Corrosion protection of magnesium and its alloys by metal phosphate conversion coatings. Surf Eng, 2014, 30: 871-879

19 Riaz U, Shabib I, Haider W. The current trends of $\mathrm{Mg}$ alloys in biomedical applications-A review. J Biomed Mater Res, 2019, 107: 1970-1996

20 Chen XB, Birbilis N, Abbott TB. A simple route towards a hydroxyapatite- $\mathrm{Mg}(\mathrm{OH})_{2}$ conversion coating for magnesium. Corrosion Sci, 2011, 53: 2263-2268

$21 \mathrm{Xu} \mathrm{L}$, Pan F, Yu G, et al. In vitro and in vivo evaluation of the surface bioactivity of a calcium phosphate coated magnesium alloy. Biomaterials, 2009, 30: 1512-1523

22 Liu J, Zheng Y, Bi Y, et al. Improved cytocompatibility of Mg-1Ca alloy modified by $\mathrm{Zn}$ ion implantation and deposition. Mater
Lett, 2017, 205: 87-89

23 Cheng M, Qiao Y, Wang Q, et al. Dual ions implantation of zirconium and nitrogen into magnesium alloys for enhanced corrosion resistance, antimicrobial activity and biocompatibility. Colloids Surfs B-Biointerfaces, 2016, 148: 200-210

24 Wu G, Ding K, Zeng X, et al. Improving corrosion resistance of titanium-coated magnesium alloy by modifying surface characteristics of magnesium alloy prior to titanium coating deposition. Scripta Mater, 2009, 61: 269-272

$25 \mathrm{Wu} \mathrm{H}, \mathrm{Wu}$ G, Chu PK. Effects of cerium ion implantation on the corrosion behavior of magnesium in different biological media. Surf Coat Tech, 2016, 306: 6-10

26 Cui LY, Qin PH, Huang XL, et al. Electrodeposition of $\mathrm{TiO}_{2}$ layer-by-layer assembled composite coating and silane treatment on $\mathrm{Mg}$ alloy for corrosion resistance. Surf Coat Tech, 2017, 324: 560-568

27 Shangguan $\mathrm{Y}$, Wan $\mathrm{P}$, Tan $\mathrm{L}$, et al. Investigation of the inner corrosion layer formed in pulse electrodeposition coating on $\mathrm{Mg}$ Sr alloy and corresponding degradation behavior. J Colloid Interface Sci, 2016, 481: 1-12

28 Qiu X, Wan P, Tan LL, et al. Preliminary research on a novel bioactive silicon doped calcium phosphate coating on AZ31 magnesium alloy via electrodeposition. Mater Sci Eng-C, 2014, 36: $65-76$

29 Jia L, Liang C, Huang N, et al. Morphology and composition of coatings based on hydroxyapatite-chitosan- $\mathrm{RuCl}_{3}$ system on AZ91D prepared by pulsed electrochemical deposition. J Alloys Compd, 2016, 656: 961-971

30 Kang Z, Li W. Facile and fast fabrication of superhydrophobic surface on magnesium alloy by one-step electrodeposition method. J Ind Eng Chem, 2017, 50: 50-56

31 Ostrowski N, Lee B, Enick N, et al. Corrosion protection and improved cytocompatibility of biodegradable polymeric layer-bylayer coatings on AZ31 magnesium alloys. Acta Biomater, 2013, 9: $8704-8713$

32 Chen L, Bromberg L, Lee JA, et al. Multifunctional electrospun fabrics via layer-by-layer electrostatic assembly for chemical and biological protection. Chem Mater, 2010, 22: 1429-1436

33 Tan Q, Ji J, Barbosa MA, et al. Constructing thromboresistant surface on biomedical stainless steel via layer-by-layer deposition anticoagulant. Biomaterials, 2003, 24: 4699-4705

34 Borges J, Mano JF. Molecular interactions driving the layer-bylayer assembly of multilayers. Chem Rev, 2014, 114: 8883-8942

35 Zeng $\mathrm{R}$, Liu L, Luo $\mathrm{K}$, et al. In vitro corrosion and antibacterial properties of layer-by-layer assembled GS/PSS coating on AZ31 magnesium alloys. Trans Nonferrous Met Soc China, 2015, 25: 4028-4039

36 Liu L, Li P, Zou $\mathrm{Y}$, et al. In vitro corrosion and antibacterial performance of polysiloxane and poly(acrylic acid)/gentamicin sulfate composite coatings on AZ31 alloy. Surf Coat Tech, 2016, 291: 7-14

37 He LJ, Hao JC, Dai L, et al. Layer-by-layer assembly of gentamicin-based antibacterial multilayers on Ti alloy. Mater Lett, 2020, 261: 127001

38 Cai K, Sui X, Hu Y, et al. Fabrication of anticorrosive multilayer onto magnesium alloy substrates via spin-assisted layer-by-layer technique. Mater Sci Eng-C, 2011, 31: 1800-1808

39 Decher G. Fuzzy nanoassemblies: Toward layered polymeric multicomposites. Science, 1997, 277: 1232-1237

40 Izumrudov VA, Mussabayeva BK, Murzagulova KB. Polyelec- 
trolyte multilayers: Preparation and applications. Russ Chem Rev, 2018, 87: 192-200

41 Sukhishvili SA. Responsive polymer films and capsules via layerby-layer assembly. Curr Opin Colloid Interface Sci, 2005, 10: 3744

42 Cai K, Rechtenbach A, Hao J, et al. Polysaccharide-protein surface modification of titanium via a layer-by-layer technique: Characterization and cell behaviour aspects. Biomaterials, 2005, 26: 5960-5971

43 Tong W, Gao C. Multilayer microcapsules with tailored structures for bio-related applications. J Mater Chem, 2008, 18: 37993812

44 Cui $\mathrm{L}, \mathrm{Xu} \mathrm{J}, \mathrm{Lu} \mathrm{N}$, et al. In vitro corrosion resistance and antibacterial properties of layer-by-layer assembled chitosan/poly- $L$ glutamic acid coating on AZ31 magnesium alloys. Trans Nonferrous Met Soc China, 2017, 27: 1081-1086

45 Belbekhouche S, Bousserrhine N, Alphonse V, et al. Chitosan based self-assembled nanocapsules as antibacterial agent. Colloids Surfs B-Biointerfaces, 2019, 181: 158-165

46 Postma A, Yan Y, Wang Y, et al. Self-polymerization of dopamine as a versatile and robust technique to prepare polymer capsules. Chem Mater, 2009, 21: 3042-3044

47 Abdelkebir K, Morin-Grognet S, Gaudière F, et al. Biomimetic layer-by-layer templates for calcium phosphate biomineralization. Acta Biomater, 2012, 8: 3419-3428

48 Lavalle P, Voegel JC, Vautier D, et al. Dynamic aspects of films prepared by a sequential deposition of species: Perspectives for smart and responsive materials. Adv Mater, 2011, 23: 1191-1221

49 Chen Y, Wang J, Dou J, et al. Layer by layer assembled chitosan $\left(\mathrm{TiO}_{2}\right)$-heparin composite coatings on MAO-coated $\mathrm{Mg}$ alloys. Mater Lett, 2020, 281: 128640

50 Ji XJ, Luan GF, Lyu JC, et al. Corrosion resistance and tunable release of ciprofloxacin-loaded multilayers on magnesium alloy: Effects of $\mathrm{SiO}_{2}$ nanoparticles. Appl Surf Sci, 2020, 508: 145240

51 Hlushko R, Ankner JF, Sukhishvili SA. Layer-by-layer hydrogenbonded antioxidant films of linear synthetic polyphenols. Macromolecules, 2020, 53: 1033-1042

52 Gao F, Hu Y, Li G, et al. Layer-by-layer deposition of bioactive layers on magnesium alloy stent materials to improve corrosion resistance and biocompatibility. Bioactive Mater, 2020, 5: 611623

53 Chen L, Tseng CM, Qiu Y, et al. A layer-by-layer assembled coating for improved stress corrosion cracking on biomedical magnesium alloy in cell culture medium. Surf Coat Tech, 2020, 403: 126427

54 Zhang X, Yi J, Zhao G, et al. Layer-by-layer assembly of silver nanoparticles embedded polyelectrolyte multilayer on magnesium alloy with enhanced antibacterial property. Surf Coat Tech, 2016, 286: 103-112

55 Puniredd SR, Srinivasan MP. Covalent molecular assembly in supercritical carbon dioxide: A comparative study between amine- and anhydride-derivatized surfaces. Langmuir, 2006, 22: 4092-4099

56 Wang XR, Chen X (eds.). Novel Nanomaterials for Biomedical, Environmental and Energy Applications. New York: Elsevier, 2019

57 He X, Zhang G, Pei Y, et al. Layered hydroxide/polydopamine/ hyaluronic acid functionalized magnesium alloys for enhanced anticorrosion, biocompatibility and antithrombogenicity in vascular stents. J Biomater Appl, 2020, 34: 1131-1141
58 Wang L, Wang Z, Zhang X, et al. A new approach for the fabrication of an alternating multilayer film of poly(4-vinylpyridine) and poly(acrylic acid) based on hydrogen bonding. Macromol Rapid Commun, 1997, 18: 509-514

59 Sundaramurthy A, Vergaelen M, Maji S, et al. Hydrogen bonded multilayer films based on poly(2-oxazoline)s and tannic acid. Adv Healthcare Mater, 2014, 3: 2040-2047

60 Zhao YB, Liu HP, Li CY, et al. Corrosion resistance and adhesion strength of a spin-assisted layer-by-layer assembled coating on AZ31 magnesium alloy. Appl Surf Sci, 2018, 434: 787-795

$61 \mathrm{Chu}$ JH, Tong LB, Zhang JB, et al. Bio-inspired graphene-based coatings on $\mathrm{Mg}$ alloy surfaces and their integrations of anti-corrosive/wearable performances. Carbon, 2019, 141: 154-168

62 Hornberger H, Virtanen S, Boccaccini AR. Biomedical coatings on magnesium alloys-A review. Acta Biomater, 2012, 8: 24422455

63 Shimazaki Y, Mitsuishi M, Ito S, et al. Preparation of the layer-bylayer deposited ultrathin film based on the charge-transfer interaction. Langmuir, 1997, 13: 1385-1387

64 Keeney M, Jiang XY, Yamane M, et al. Nanocoating for biomolecule delivery using layer-by-layer self-assembly. J Mater Chem B, 2015, 3: 8757-8770

65 Meier H. Conjugated oligomers with terminal donor-acceptor substitution. Angew Chem Int Ed, 2005, 44: 2482-2506

66 Topuz F, Möller M, Groll J. Covalently layer-by-layer assembled homogeneous nanolayers with switchable wettability. Polym Chem, 2015, 6: 4690-4697

67 Buck ME, Breitbach AS, Belgrade SK, et al. Chemical modification of reactive multilayered films fabricated from poly(2-alkenyl azlactone)s: Design of surfaces that prevent or promote mammalian cell adhesion and bacterial biofilm growth. Biomacromolecules, 2009, 10: 1564-1574

68 Zhang Y, He H, Gao C, et al. Covalent layer-by-layer functionalization of multiwalled carbon nanotubes by click chemistry. Langmuir, 2009, 25: 5814-5824

69 Feng X, Cumurcu A, Sui X, et al. Covalent layer-by-layer assembly of redox-active polymer multilayers. Langmuir, 2013, 29: 7257-7265

70 Zhang H, Wang Z, Zhang Y, et al. Hydrogen-bonding-directed layer-by-layer assembly of poly(4-vinylpyridine) and poly(4-vinylphenol): Effect of solvent composition on multilayer buildup. Langmuir, 2004, 20: 9366-9370

71 Such GK, Johnston APR, Caruso F. Engineered hydrogen-bonded polymer multilayers: From assembly to biomedical applications. Chem Soc Rev, 2011, 40: 19-29

72 Zhang X, Shen J. Self-assembled ultrathin films: From layered nanoarchitectures to functional assemblies. Adv Mater, 1999, 11: 1139-1143

73 Wang X, Naka K, Itoh H, et al. Preparation of oriented ultrathin films via self-assembly based on charge transfer interaction between $\pi$-conjugated poly(dithiafulvene) and acceptor polymer. Macromolecules, 2003, 36: 533-535

74 Zhang $\mathrm{X}$, Chen $\mathrm{H}$, Zhang H. Layer-by-layer assembly: From conventional to unconventional methods. Chem Commun, 2007, 14: $1395-1405$

75 Krogman KC, Lowery JL, Zacharia NS, et al. Spraying asymmetry into functional membranes layer-by-layer. Nat Mater, 2009, 8: 512-518

76 Cho J, Char K, Hong JD, et al. Fabrication of highly ordered multilayer films using a spin self-assembly method. Adv Mater, 
2001, 13: 1076-1078

77 Tang Q, Tang Z, Wu J, et al. Highly conducting multilayer films from graphene nanosheets by a spin self-assembly method. J Mater Chem, 2011, 21: 5378-5385

78 Guzmán E, Rubio RG, Ortega F. A closer physico-chemical look to the layer-by-layer electrostatic self-assembly of polyelectrolyte multilayers. Adv Colloid Interface Sci, 2020, 282: 102197

79 Xiang Y, Lu S, Jiang SP. Layer-by-layer self-assembly in the development of electrochemical energy conversion and storage devices from fuel cells to supercapacitors. Chem Soc Rev, 2012, 41: 7291-7321

80 Shim BS, Podsiadlo P, Lilly DG, et al. Nanostructured thin films made by dewetting method of layer-by-layer assembly. Nano Lett, 2007, 7: 3266-3273

81 Reiter G, Demirel AL, Granick S. From static to kinetic friction in confined liquid films. Science, 1994, 263: 1741-1744

82 Li Y, Wang X, Sun J. Layer-by-layer assembly for rapid fabrication of thick polymeric films. Chem Soc Rev, 2012, 41: 5998-6009

$83 \mathrm{Fu} \mathrm{Y,} \mathrm{Li} \mathrm{SJ,} \mathrm{Xu} \mathrm{J,} \mathrm{et} \mathrm{al.} \mathrm{Facile} \mathrm{and} \mathrm{efficient} \mathrm{approach} \mathrm{to} \mathrm{speed} \mathrm{up}$ layer-by-layer assembly: Dipping in agitated solutions. Langmuir, 2011, 27: 672-677

84 Kiel M, Mitzscherling S, Leitenberger W, et al. Structural characterization of a spin-assisted colloid-polyelectrolyte assembly: Stratified multilayer thin films. Langmuir, 2010, 26: 18499-18502

85 Kharlampieva E, Kozlovskaya V, Chan J, et al. Spin-assisted layerby-layer assembly: Variation of stratification as studied with neutron reflectivity. Langmuir, 2009, 25: 14017-14024

86 Schlenoff JB, Dubas ST, Farhat T. Sprayed polyelectrolyte multilayers. Langmuir, 2000, 16: 9968-9969

87 Dierendonck M, De Koker S, De Rycke R, et al. Just spray it-LbL assembly enters a new age. Soft Matter, 2014, 10: 804-807

88 Lefort M, Boulmedais F, Jierry L, et al. Simultaneous spray coating of interacting species: General rules governing the poly (styrene sulfonate)/poly(allylamine) system. Langmuir, 2011, 27: 4653-4660

89 Lefort M, Popa G, Seyrek E, et al. Spray-on organic/inorganic films: A general method for the formation of functional nano- to microscale coatings. Angew Chem Int Ed, 2010, 49: 10110-10113

90 Cui LY, Fang XH, Cao W, et al. In vitro corrosion resistance of a layer-by-layer assembled DNA coating on magnesium alloy. Appl Surf Sci, 2018, 457: 49-58

91 van den Beucken JJJP, Walboomers XF, Leeuwenburgh SCG, et al. Multilayered DNA coatings: In vitro bioactivity studies and effects on osteoblast-like cell behavior. Acta Biomater, 2007, 3 : 587-596

92 Gao F, Hu Y, Gong Z, et al. Fabrication of chitosan/heparinized graphene oxide multilayer coating to improve corrosion resistance and biocompatibility of magnesium alloys. Mater Sci Eng-C, 2019, 104: 109947

93 Pan CJ, Hou YH, Zhang BB, et al. Blood compatibility and interaction with endothelial cells of titanium modified by sequential immobilization of poly (ethylene glycol) and heparin. J Mater Chem B, 2014, 2: 892-902

94 Liu T, Hu Y, Tan J, et al. Surface biomimetic modification with laminin-loaded heparin/poly- $L$-lysine nanoparticles for improving the biocompatibility. Mater Sci Eng-C, 2017, 71: 929-936

95 Khor E, Lim LY. Implantable applications of chitin and chitosan. Biomaterials, 2003, 24: 2339-2349

96 Chen Y, Li J, Yang W, et al. Enhanced corrosion protective performance of graphene oxide-based composite films on AZ31 magnesium alloys in $3.5 \mathrm{wt} \% \mathrm{NaCl}$ solution. Appl Surf Sci, 2019, 493: $1224-1235$

97 Zhang B, Yao R, Li L, et al. Green tea polyphenol induced $\mathrm{Mg}^{2+}$-rich multilayer conversion coating: Toward enhanced corrosion resistance and promoted in situ endothelialization of AZ31 for potential cardiovascular applications. ACS Appl Mater Interfaces, 2019, 11: 41165-41177

98 Zhao Y, Zhang Z, Shi L, et al. Corrosion resistance of a selfhealing multilayer film based on $\mathrm{SiO}_{2}$ and $\mathrm{CeO}_{2}$ nanoparticles layer-by-layer assembly on $\mathrm{Mg}$ alloys. Mater Lett, 2019, 237: 1418

99 Zhuang Y, Ren L, Zhang S, et al. Antibacterial effect of a coppercontaining titanium alloy against implant-associated infection induced by methicillin-resistant Staphylococcus aureus. Acta Biomater, 2021, 119: 472-484

100 Kenawy ER, Worley SD, Broughton R. The chemistry and applications of antimicrobial polymers: A state-of-the-art review. Biomacromolecules, 2007, 8: 1359-1384

101 Patil D, Wasson MK, Aravindan S, et al. Antibacterial and cytocompatibility study of modified Ti6Al4V surfaces through thermal annealing. Mater Sci Eng-C, 2019, 99: 1007-1020

102 Hassoun A, Linden PK, Friedman B. Incidence, prevalence, and management of MRSA bacteremia across patient populations-A review of recent developments in MRSA management and treatment. Crit Care, 2017, 21: 211

103 Wang B, Ren $\mathrm{K}$, Chang $\mathrm{H}$, et al. Construction of degradable multilayer films for enhanced antibacterial properties. ACS Appl Mater Interfaces, 2013, 5: 4136-4143

104 Song MS, Zeng RC, Ding YF, et al. Recent advances in biodegradation controls over $\mathrm{Mg}$ alloys for bone fracture management: A review. J Mater Sci Tech, 2019, 35: 535-544

105 Ao HY, Yang SB, Nie BE, et al. Improved antibacterial properties of collagen I/hyaluronic acid/quaternized chitosan multilayer modified titanium coatings with both contact-killing and releasekilling functions. J Mater Chem B, 2019, 7: 1951-1961

106 Escobar A, Muzzio N, Moya SE. Antibacterial layer-by-layer coatings for medical implants. Pharmaceutics, 2020, 13: 16

107 Cloutier M, Mantovani D, Rosei F. Antibacterial coatings: Challenges, perspectives, and opportunities. Trends Biotech, 2015, 33: 637-652

108 Hardes J, Ahrens H, Gebert C, et al. Lack of toxicological sideeffects in silver-coated megaprostheses in humans. Biomaterials, 2007, 28: 2869-2875

109 Wang B, Zhao L, Zhu W, et al. Mussel-inspired nano-multilayered coating on magnesium alloys for enhanced corrosion resistance and antibacterial property. Colloids Surfs B-Biointerfaces, 2017, 157: 432-439

110 Rabea EI, Badawy MET, Stevens CV, et al. Chitosan as antimicrobial agent: Applications and mode of action. Biomacromolecules, 2003, 4: 1457-1465

111 Zhao L, Wang $\mathrm{H}$, Huo $\mathrm{K}$, et al. Antibacterial nano-structured titania coating incorporated with silver nanoparticles. Biomaterials, 2011, 32: 5706-5716

112 Zeng R, Liu L, Li S, et al. Self-assembled silane film and silver nanoparticles coating on magnesium alloys for corrosion resistance and antibacterial applications. Acta Metall Sin, 2013, 26: 681-686

113 Zhao Y, Shi L, Ji X, et al. Corrosion resistance and antibacterial properties of polysiloxane modified layer-by-layer assembled selfhealing coating on magnesium alloy. J Colloid Interface Sci, 2018, 
526: 43-50

114 Ji XJ, Gao L, Liu JC, et al. Corrosion resistance and antibacterial activity of hydroxyapatite coating induced by ciprofloxacinloaded polymeric multilayers on magnesium alloy. Prog Org Coat, 2019, 135: 465-474

115 Masadeh MM, Alzoubi KH, Khabour OF, et al. Ciprofloxacininduced antibacterial activity is attenuated by phosphodiesterase inhibitors. Curr Therapeutic Res, 2015, 77: 14-17

116 Zhao Y, Chen X, Li S, et al. Corrosion resistance and drug release profile of gentamicin-loaded polyelectrolyte multilayers on magnesium alloys: Effects of heat treatment. J Colloid Interface Sci, 2019, 547: 309-317

117 Ma M, Liu X, Tan L, et al. Enhancing the antibacterial efficacy of low-dose gentamicin with 5 minute assistance of photothermy at $50^{\circ} \mathrm{C}$. Biomater Sci, 2019, 7: 1437-1447

118 Liu P, Hao Y, Zhao Y, et al. Surface modification of titanium substrates for enhanced osteogenetic and antibacterial properties. Colloids Surfs B-Biointerfaces, 2017, 160: 110-116

119 Shen J, Jin B, Qi YC, et al. Carboxylated chitosan/silver-hydroxyapatite hybrid microspheres with improved antibacterial activity and cytocompatibility. Mater Sci Eng-C, 2017, 78: 589-597

120 Yu Y, Tao B, Sun J, et al. Fabrication of chitosan-graft-polyaniline-based multilayers on $\mathrm{Ti}$ substrates for enhancing antibacterial property and improving osteogenic activity. Mater Lett, 2020, 268: 127420

121 Kamrani S, Fleck C. Biodegradable magnesium alloys as temporary orthopaedic implants: A review. BioMetals, 2019, 32: 185193

122 Quan L, Ge SP, Liu CY, et al. Impact of a bioactive drug coating on the biocompatibility of magnesium alloys. J Mater Sci, 2020, 55: 6051-6064

123 Ji XJ, Gao L, Liu JC, et al. Corrosion resistance and antibacterial properties of hydroxyapatite coating induced by gentamicinloaded polymeric multilayers on magnesium alloys. Colloids Surfs B-Biointerfaces, 2019, 179: 429-436

124 Cui LY, Cheng SC, Liang LX, et al. In vitro corrosion resistance of layer-by-layer assembled polyacrylic acid multilayers induced Ca$\mathrm{P}$ coating on magnesium alloy AZ31. Bioactive Mater, 2020, 5: 153-163

125 Fan F, Zhou C, Wang X, et al. Layer-by-layer assembly of a selfhealing anticorrosion coating on magnesium alloys. ACS Appl Mater Interfaces, 2015, 7: 27271-27278

126 Liu L, Yang Q, Huang L, et al. The effects of a phytic acid/calcium ion conversion coating on the corrosion behavior and osteoinductivity of a magnesium-strontium alloy. Appl Surf Sci, 2019, 484: 511-523

Acknowledgements This work was supported by the National Natural Science Foundation of China (52071191), Shandong University of Science and Technology (SDUST) Research Fund (2014TDJH104) and the Science and Technology Innovation Fund of SDUST for graduate students (SDKDYC180371).

Author contributions $\mathrm{He}$ LJ and Shao Y wrote the paper with support from Zeng RC. Li SQ, Ji XJ, Zhao YB and Cui LY modified this review article. All authors contributed to the final version of the manuscript.

Conflict of interest The authors declare that they have no conflict of interest.

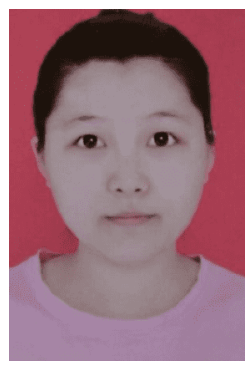

Li-Jun He received her BE degree from Shandong University of Science and Technology in 2019 and is now a $\mathrm{PhD}$ candidate at the university. Her research interest is mainly focused on the design and construction of layer-by-layer assembly functional coating.

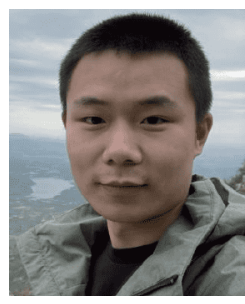

Yang Shao received his BE degree from Shandong University of Science and Technology in 2019 and is now a MS student at the university. His research mainly covers biomedical metal surface modification, corrosion and protection of metals.

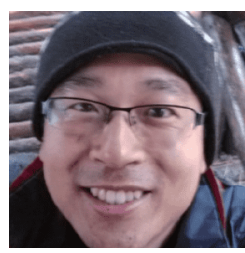

Shuo-Qi Li is an associate professor at the College of Materials Science and Engineering, Shandong University of Science and Technology. He received his $\mathrm{PhD}$ degree from Beijing Normal University in 2012. His research is mainly concentrated on layer-by-layer self-assembled coatings on biodegradable magnesium alloys.

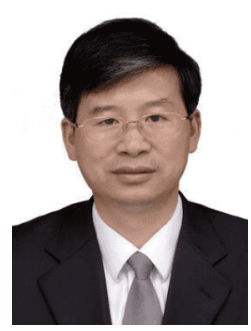

Rong-Chang Zeng is currently a professor at the College of Materials Science and Engineering, Shandong University of Science and Technology. He received his $\mathrm{PhD}$ degree from the Institute of Metal Research, Chinese Academy of Sciences in 2003. He is currently editorial board member of Bioactive Materials, Journal of Magnesium and Alloys, and Frontiers of Materials Science, etc. His research interest is focused on corrosion and protection of metals, biodegradable magnesium alloys and surface functionalized modification.

\section{生物可降解镁合金层层自组装涂层的研究进展}

何丽君 ${ }^{\dagger}$, 郡阳 ${ }^{\dagger}$, 李硕琦 ${ }^{*}$, 崔蓝月, 纪晓静, 赵延斌, 曾荣昌 ${ }^{*}$

摘要 镁及其合金由于优异的机械性能和生物相容性而被认为是 理想的可生物降解材料. 为了改善其表面性能以更好地适应人体 周围的组织环境, 表面修饰和处理在满足多种临床要求(如耐腐蚀 性、生物相容性和抗菌能力)方面发挥了重要作用. 在可生物降解 镁合金的表面处理技术中，层层自组装技术因为可以选择多种可 用的组装单元而具有广阔的应用前景. 本文综述了生物可降解镁 合金层层自组装驱动力 (静电相互作用、氢键作用、电荷转移相互 作用和共价键结合)的机理、制备方法(如浸渍法、喷涂法和旋涂 法)的研究进展, 以及涂层所具有的功能特性(耐腐蚀性、抗菌活性 和生物相容性). 最后, 我们从表面改性的角度提出了层层自组装技 术在生物镁合金表面应用的发展趋势. 